\title{
Fetus Small for Gestational Age with Abnormal Doppler
}

National Cancer Institute

\section{Source}

National Cancer Institute. Fetus Small for Gestational Age with Abnormal Doppler. NCI

Thesaurus. Code C114877.

A fetus that does not grow beyond the 10th percentile of conventionally accepted weight

for gestational age and has abnormal Doppler studies. 